$\S=-1$

\title{
Predicting the dynamic behavior of classical columns using two- dimensional models
}

\author{
Dimitrios K. Baros ${ }^{1}$, Angeliki Papalou ${ }^{1 *}$ \\ ${ }^{1}$ Department of Civil Engineering, TEI of Western Greece 26334 Patras, Greece \\ *Corresponding author E-mail: papalou@teiwest.gr
}

\begin{abstract}
Ancient temples consisting of classical columns have been exposed through the years to dynamic loads with sometimes detrimental effects. Predicting their dynamic behavior is important for their restoration and preservation. This paper analyzes the behavior of classical columns under dynamic loading using simplified two-dimensional finite element models. The adequacy of these models for the prediction of the dynamic behavior of classical columns is verified comparing the numerical results with experimental measurements. The most important parameters that influence the model's behavior are identified. The behavior of classical columns can be predicted in the direction of excitation with reasonable accuracy using two-dimensional finite element models when the properties of the models are selected appropriately.
\end{abstract}

Keywords: Monuments; Classical Column; Multi-Drum Column; Finite Elements; Dynamic Loads.

\section{Introduction}

During the last years, special attention has been given in the preservation of cultural monuments that are exposed to environmental conditions and seismic activities. Ancient temples located in the Mediterranean Sea are unique structures consisting of multidrum columns used to support the roof of the temples. The deterioration of these columns through the years has increased their vulnerability to earthquakes. Predicting their seismic response is important in order to find appropriate methods to restore and preserve them. The dynamic behavior of multi-drum columns is highly nonlinear and cannot be estimated easily with analytical methods. Previous research that examined the dynamic response of these complex structures was based either on experimental work on scaled-models or simulations with finite elements, finite differences, boundary elements and distinct elements [1-20]. These studies focused mostly on three-dimensional models that can better simulate the rotation of the drums around the vertical axis and the out of plane motion. However, simplified two-dimensional finite element models are easier to formulate, limit the computational load and can be a useful first step for the investigation of the dynamic response of complex structures.

In this work, the dynamic behavior of classical columns is investigated using a two-dimensional finite element model. The numerical results are compared with available experimental measurements [15]. The sensitivity of the dynamic response of the classical columns to various model parameters is quantified.

\section{Geometry of model and measurements}

The geometry of the two dimensional-model used for the numerical analysis was based on an actual 3-m eleven-drum column (Figure 1) used for experimental tests [15].

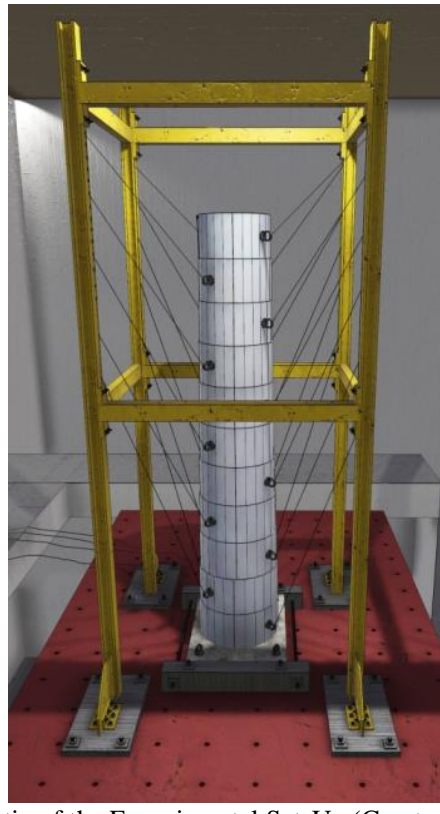

Fig. 1: A Schematic of the Experimental Set-Up (Created by M. Miaoulis).

The height and weight of the column were $0.584 \mathrm{~m}$ and $1.7 \mathrm{tn}$ respectively. The diameter of the drums decreased linearly from $0.584 \mathrm{~m}$ at the base to $0.445 \mathrm{~m}$ at the top. The drums were lying one above the other having contact only at the outer part of their top horizontal surface through a peripheral ring smoothly polished, while the rest remained unpolished and slightly indented. There were no links connecting the drums. The column was placed on a marble plate of the following dimensions: $0.9 \mathrm{~m}$ height; $0.7 \mathrm{~m}$ width and $0.14 \mathrm{~m}$ thickness. The whole arrangement was placed on a shake table that could perform seismic simulation in one direction. A steel frame surrounded the column and loose ropes were connecting it with the drums to avoid their accidental fall. 
Accelerometers were placed at the top of the column and at several other locations throughout the column. The acceleration of the shaker was also measured via a built-in accelerometer. The accelerations were doubly integrated to obtain the corresponding displacements. A random signal of $10 \mathrm{sec}$ duration, containing frequencies from 0 to $10 \mathrm{~Hz}$ was used for the investigation (Figure 2).

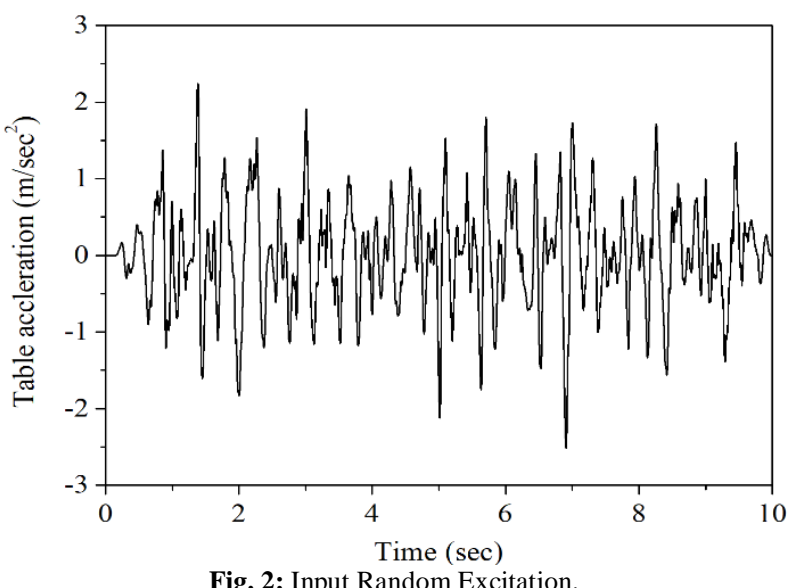

\section{Numerical approach}

A two-dimensional (2-D) finite element model (using the ANSYS computer software) was created to simulate the dynamic response of the 3-m marble multi-drum column described in the previous section (Figure 3). The planar approximation of the problem can be considered acceptable in this case, since the experimental results were obtained considering one component of seismic excitation. Moreover 2-D models are easier to process, providing a more suitable solution for everyday application.

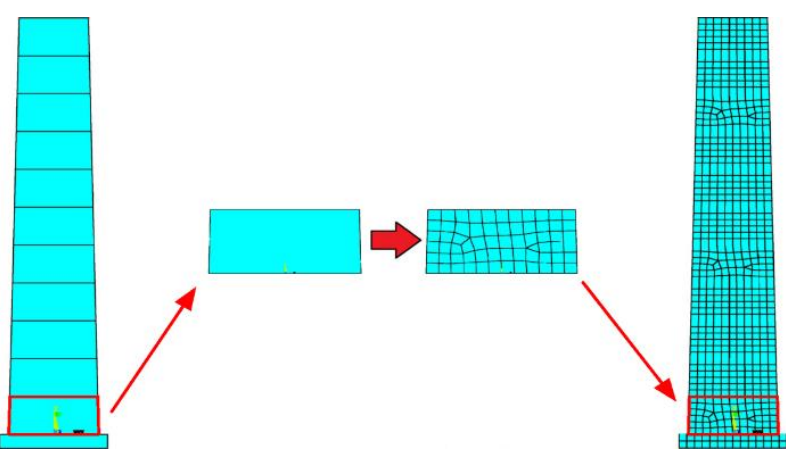

Fig. 3: The 2-D Finite Element Model of the Column.

Each drum was represented by a separate trapezoidal area and meshed as a deformable block using higher order plane elements. The element used is an eight-node axisymmetric-harmonic, high order element, with three degrees of freedom per node (translations in the nodal $\mathrm{x}, \mathrm{y}$ and $\mathrm{z}$ directions). The element was selected since it provides more accurate results for mixed (quadrilateraltriangular) meshes and can tolerate irregular shapes without as much loss of accuracy [21]. The modulus of elasticity and Poisson's ratio were set to $25 \mathrm{GPa}$ and 0.25 respectively. The number of elements was chosen in order to balance the accuracy of the results and the requirement of reduced analysis times. The 2-D model consisted of 693 elements (2477 nodes). To reduce the computational time and complexity of the model the smoothly polished ring at the top of each drum was neglected.

The contact between the drums was simulated using a pair of contact elements, each element representing one area (face) of the interface (usually identified as "target" and "contact" area). The selected 2-D contact elements are appropriate for the simulation of surface-to-surface contacts in planar models using the augmented Lagrange algorithm. This approach allows the identification of new contacts either at the nodes or at the integration points inside the contact faces. This formulation can represent successfully the motion of the drums including sliding and rocking. The total number of elements of the model, including those employed for the representation of the contacts' behavior was 923 .

The dynamic response of the column depends on the friction between the drums, the normal stiffness of the contact areas and the damping. The friction that occurs when surfaces in contact are sliding was simulated using the Coulomb friction model. Values of $\mu=0.3$ and $\mu=0.4$ were selected for the friction coefficient $\mu$ based on the experimental results. The rocking of the drums was controlled through the normal stiffness of the contact areas that adjusts the penetration of one surface inside the other. The factor (KN) that represents the normal stiffness of the closed contact areas is unknown. Higher stiffness values decrease the amount of penetration but can lead to ill-conditioning of the global stiffness matrix and to convergence difficulties [21]. Values in the range of 50-150 MPa (in ANSYS a negative sign is assigned in front of the factor) were used for $\mathrm{KN}$ in different tests.

Rayleigh damping is in general represented by a mass proportional and a stiffness proportional element. Their values were obtained from the first two modes of the column when moving parallel to the excitation. These two modes were corresponding to the first two natural frequencies of the column identified at 1.29 and 3.85 $\mathrm{Hz}$ respectively. The analysis showed that satisfactory results could be obtained employing only the first mode and the corresponding mass proportional element, simplifying the procedure even further. In the model the Rayleigh damping was introduced assigning values to the damping ratio $\zeta$ in the range from 0 to $10 \%$. This two-dimensional model with the properties and assumptions made reduced the analysis time and output load by almost $80 \%$ compared to a possible 3-D FE representation of the column.

\section{Results and discussion}

Results are presented for the top drum in the direction of the excitation in which the dynamic response of the column was highest. Figure 4 shows the predicted and observed relative displacement of the top drum with respect to the base for damping ratio $\zeta=5 \%$, friction coefficient $\mu=0.3$, and normal stiffness factor $\mathrm{KN}=100$ $\mathrm{MPa} / \mathrm{m}$. During the first $10 \mathrm{~s}$, when the forced vibration occurred, the predicted and observed response were in reasonable agreement while there was a great difference for the free vibration part of the response. In this last part of motion not only the amplitudes of the displacements differed substantially but also the predicted response exhibited a considerable residual displacement that was not observed in the experiment. By increasing the damping ratio, the free vibration part of the numerical response was reduced significantly with the trade of higher discrepancy of the numerical and observed response in the forced part of motion (Figure 5). Values of the damping ratio less than $5 \%$ result in a better agreement of the predicted and observed response in the forced part of the vibration, though substantially increasing the difference in the free vibration part.

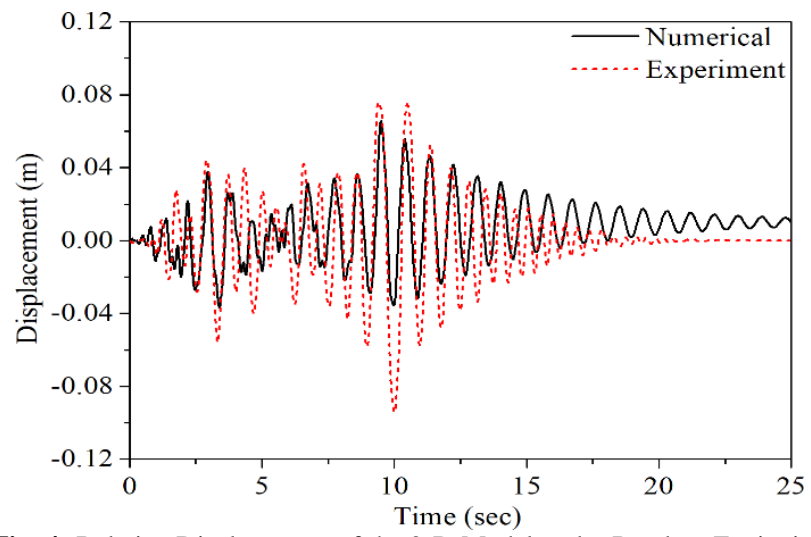

Fig. 4: Relative Displacement of the 2-D Model under Random Excitation with the $\mathrm{KN}=100 \mathrm{MPa} / \mathrm{m}, \mu=0.30$ and $\zeta=5 \%$. 


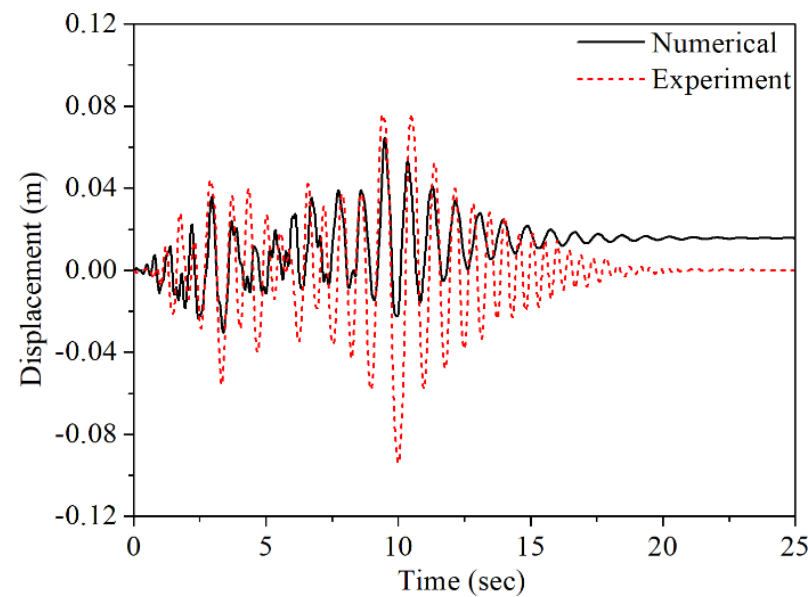

Fig. 5: Relative Displacement of the 2-D Model under Random Excitation with the $\mathrm{KN}=100 \mathrm{MPa} / \mathrm{m}, \mu=0.30$ and $\zeta=10 \%$.

The coefficient of friction also plays an important role. Increasing its value to $\mu=0.4$ led to better model performance in the free vibration regime of motion without altering significantly the results in the forced vibration part (Figure 6).

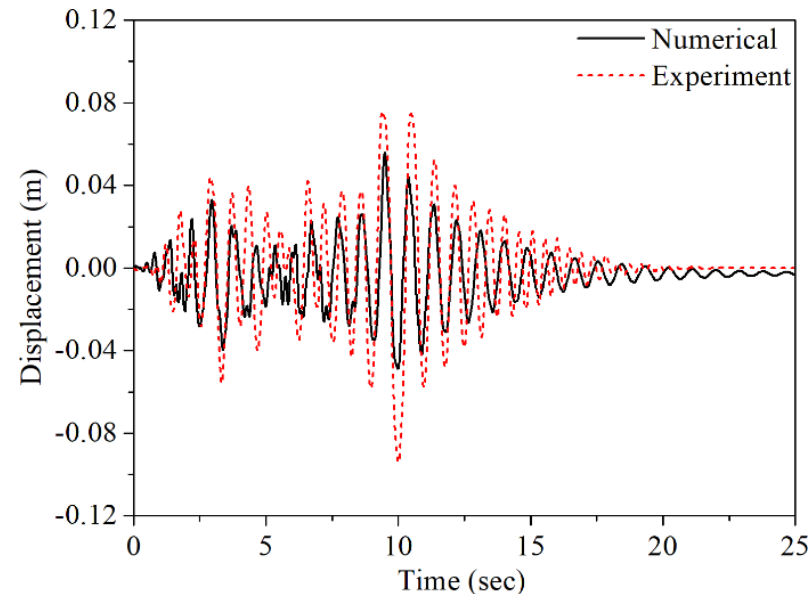

Fig. 6: Relative Displacement of the 2-D Model under Random Excitation with the $\mathrm{KN}=100 \mathrm{MPa} / \mathrm{m}, \mu=0.40$ and $\zeta=5 \%$.

The value of the normal stiffness factor is also significant. Altering its value to much higher or lower numbers than $100 \mathrm{MPa} / \mathrm{m}$ reduced the accuracy of the predicted response (Figure 7).

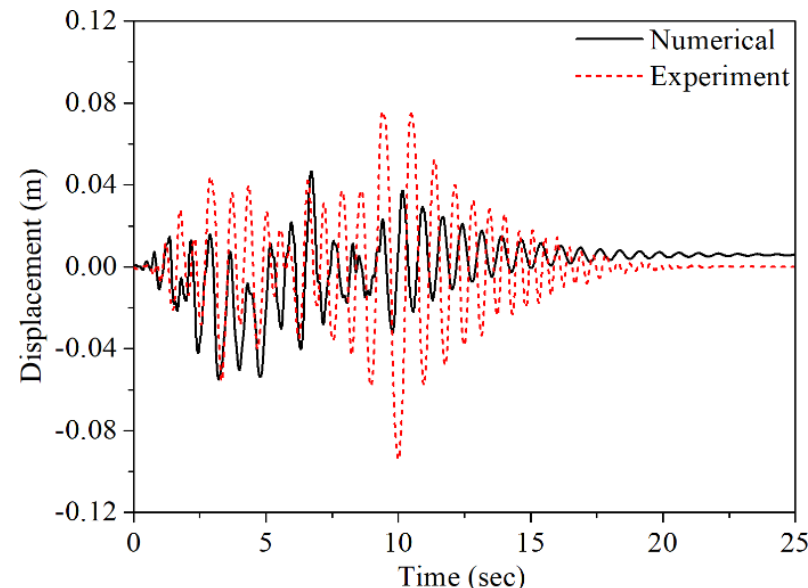

Fig. 7: Relative Displacement of the 2-D Model under Random Excitation with $\mathrm{KN}=150 \mathrm{MPa} / \mathrm{m}, \mu=0.40$ and $\zeta=5 \%$.

Use of a damping ratio equal to $5 \%$, a coefficient of friction equal to 0.4 and the normal stiffness factor of $100 \mathrm{MPa} / \mathrm{m}$ resulted in a reasonable model performance predicting the overall response of the column with somewhat smaller amplitudes. Similar observa- tions can be made using the same set of parameters for predicting the dynamic response of the column under an earthquake excitation (Figures 8-9).

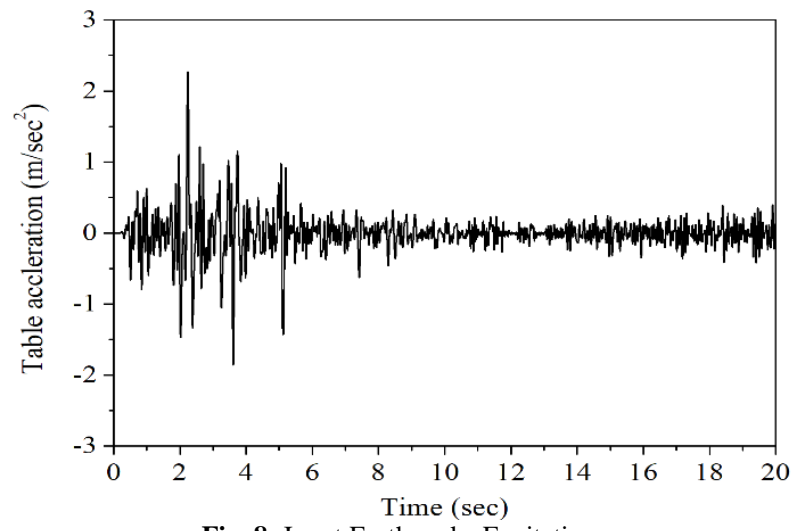

Fig. 8: Input Earthquake Excitation.

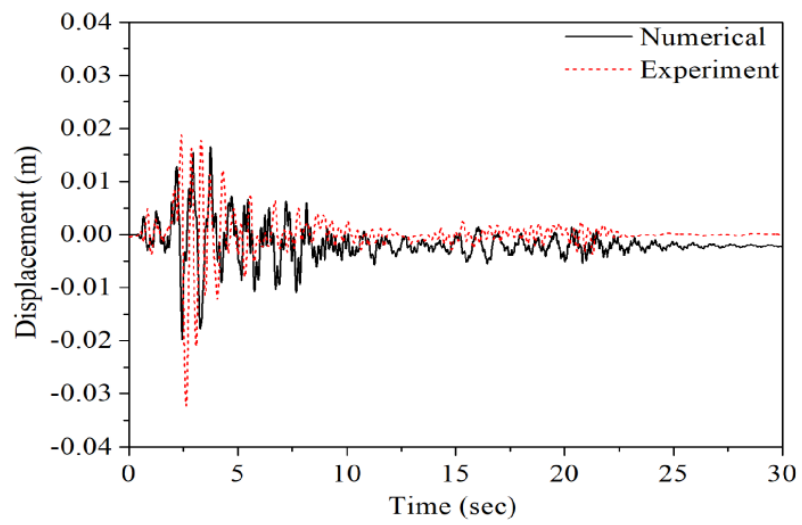

Fig. 9: Relative Displacement of the 2-D Model under Earthquake Excitation Excitation with $\mathrm{KN}=100 \mathrm{MPa} / \mathrm{m}, \mu=0.40$ and $\zeta=5 \%$.

Given the previous observations, we may conclude that a planar model with these parameter values can serve as a solid foundation for a more detailed numerical investigation considering a threedimensional model of the multi-drum column.

\section{Conclusions}

The dynamic response of classical columns was examined using two-dimensional finite element models. These simplified models can be used at initial stages of the numerical investigation, giving beneficial information of how to proceed in the analysis of structures with complex geometry in a fraction of analysis time and output load. The finite element model of a multi-drum column was created and the critical properties that affect the predicted response were identified. It was found that by selecting appropriately the properties of the finite element model a reasonable agreement can be achieved between the predicted and the observed dynamic response reducing substantially the computational load and effort.

\section{Acknowledgment}

The authors would like to thank E. Strepelias for his contribution in the experimental investigation.

\section{References}

[1] Ambraseys N and Psycharis IN. [2011] "Earthquake stability of columns and statues," Journal of Earthquake Engineering 15(5), 685-710. https://doi.org/10.1080/13632469.2010.541549.

[2] Dimitri R., De Lorenzis L., Zavarise G. [2011] "Numerical study on the dynamic behavior of masonry columns and arches on but- 
tresses with the discrete element method," Engineering Structures 33, 3172-3188. https://doi.org/10.1016/i.engstruct.2011.08.018

[3] Drosos VA and Anastasopoulos I. [2014a] "Experimental investigation of the seismic response of classical temple columns," Bulletin of Earthquake Engineering 13, 299-310 https://doi.org/10.1007/s10518-014-9608-y.

[4] Drosos V. and Anastasopoulos I. [2014b] "Shaking table testing of multidrum columns and portals," Earthquake Engineering and Structural Dynamics 43(11), 1703-1723. https://doi.org/10.1002/eqe.2418.

[5] Economou T.G. [2003] "Study of the seismic response of block connections of monuments and multi-drum constructions. Application at the Acropolis of Lindos," M.Sc. Thesis, Civil Engineering Dept., Aristotle University of Thessaloniki (in Greek).

[6] Michaltsos GT and Raftoyiannis IG. [2014] "Rocking and sliding of ancient temple columns under earthquake excitations," International Journal of Structural Stability and Dynamics 14(2). https://doi.org/10.1142/S0219455413500582.

[7] Mouzakis HP, Psycharis IN, Papastamatiou DY, Carydis PG, Papantonopoulos C and Zambas C. [2002] "Experimental investigation of the earthquake response of a model of a marble classical column," Earthquake Engineering and Structural Dynamics 31, 1681-1698. https://doi.org/10.1002/eqe.184.

[8] Papaloizou L and Komodromos P. [2009] "Planar investigation of the seismic response of ancient columns and colonnades with epistyles using a custom-made software," Soil Dynamics and Earthquake $\quad$ Engineering $29, \quad 1437-1454$ https://doi.org/10.1016/j.soildyn.2009.06.001

[9] Papaloizou L, Polycarpou P, Komodromos P, Hatzigeorgiou GD, Beskos DE. [2016] "Two-dimensional numerical investigation of the effects of multiple sequential earthquake excitations on ancient multi-drum columns," Earthquakes and Structures 10(3), 495-521. https://doi.org/10.12989/eas.2016.10.3.495.

[10] Papalou A. (2018). "The effect of particle damper's position on the dynamic response of classical columns", Periodica Polytechnica Civil Engineering 62(1), 56-63.

[11] Papalou A. (2018). "Examining the Dynamic Response of Classical Columns", International Journal of Civil Engineering 16, 123-125. https://doi.org/10.1007/s40999-016-0110-6

[12] Papalou, A. and Strepelias, E. [2014] "Structural Control of Monuments' Response under Sinusoidal Excitation using Particle Dampers," Open Construction and Building Technology Journal 8 , 351-356. https://doi.org/10.2174/1874836801408010351.

[13] Papalou A. and Strepelias E. [2015] "Effectiveness of Particle Dampers in Reducing the Monuments' Response under Dynamic Loads," Mechanics of Advanced Materials and Structures 23(2), 128-135. https://doi.org/10.1080/15376494.2014.943913.

[14] Papalou A and Strepelias E. [2015] "Control of the Dynamic Response of Classical Columns with Defects," Periodica Polytechnica Civil Engineering 59(3), 303-308 https://doi.org/10.3311/PPci.7870.

[15] Papalou A, Strepelias E, Roubien D, Bousias S, Triantafillou T [2015] "Seismic Protection of Monuments Using Particle Dampers in Multi-Drum Columns," Soil Dynamics and Earthquake Engineering 77, 360-368. https://doi.org/10.1016/j.soildyn.2015.06.004

[16] Papantonopoulos C, Psycharis IN, Papastamatiou DY, Lemos JV Mouzakis H. [2002] "Numerical prediction of the earthquake response of classical columns using the distinct element method," Earthquake Engineering and Structural Dynamics 31, 1699 -1717. https://doi.org/10.1002/eqe.185.

[17] Pitilakis K and Tavouktsi E. [2010] "Seismic response of the columns of two ancient Greek temples in Rhodes and Lindos," Proc. Of the 8th International Symposium on the Conservation of Monuments in the Mediterranean Basin, Patras, Greece.

[18] Psycharis I, Lemos J, Papastamatiou D, Zambas C, Papantonopoulos C. [2003] "Numerical study of the seismic behaviour of a part of the Parthenon Pronaos," Earthquake Engineering and Structural Dynamics 32, 2063-2084. https://doi.org/10.1002/eqe.315.

[19] Psycharis IN, Papastamatiou DY, Alexandris, AP. [2000] "Parametric investigation of the stability of classical columns under harmonic and earthquake excitations," Earthquake Engineering and Structural Dynamics 29, 1093-1109. https://doi.org/10.1002/10969845(200008)29:8<1093::AID-EQE953>3.0.CO;2-S

[20] Simo J.C. and Laursen T.A. [1992] "An augmented Lagrangian treatment of contact problems involving friction," Computers and Structures 42(1), 97-116. https://doi.org/10.1016/00457949(92)90540-G.

[21] ANSYS Inc. [2000] "ANSYS structural analysis guide", Canonsburg, PA. 